\title{
Héroes y mártires
}

Nuria Rodríguez Vargas ${ }^{1}$

"Decir la palabra verdadera es transformar el mundo"

Paulo Freire

-“Hola papi, no podremos ir para mi cumpleaños, las inundaciones de la semana pasada dejaron en muy mal estado las dos aulitas, vamos a trabajar en la restauración el fin de semana. Un beso para mami, los quiero".

Terminó de leer el mensaje de texto, sonrió y recordó... "Mi primogénita, treinta y tres años ya”. “¡Paula, Paula! Deberían ponerla Rosa en honor a la Santa Patrona de Lima, la primera Santa de América”, había sentenciado la bisabuela.

El 23 de agosto de 1980 se había convertido en papá; al finalizar el día había recibido un telegrama donde se lo informaban. ¡PUÑO EN ALTO, LIBRO ABIERTO! Algarabía, felicidad, abrazos, esperanzas... La misión terminaba, pero la transformación apenas había empezado.

...Bajó del autobús, su único equipaje era una mochila llena de sueños y un libro de Máximo Gorky. Estaba en Mana-ahuac,

1 La primera versión de este cuento fue publicada el 19 de julio de 2014, con motivo del 35 aniversario del triunfo de la Revolución Sandinista, en la página oficial de Facebook del Instituto de Estudos LatinoAmericanos (IELA), Universidad de Santa Catarina, Florianópolis, Brasil. ese puñado de agua alrededor lo había maravillado. Un mar de brigadistas, diversos acentos y nacionalidades, era la primera vez que cruzaba la frontera inventada, se sentía en casa.

Le tocó participar en la brigada del Norte; junto a cientos de jóvenes locales emprendió el camino. Se bebía los paisajes de esa tierra hermana, tan cercana y ahora tan nueva. Otro aire se respiraba, decían los compañeros, era el aire de la esperanza.

En los maizales las hojas se inclinaban con la brisa, en una hermosa bienvenida a los brigadistas. Pinol, atol, güirila, yoltamal, cususa, pozol, cuantos platos derivados de la sagrada planta. La siembra, la milpa, la recolección, la sobrevivencia, la simbiosis con el hombre, estilo de vida... hombres de maíz.

-Compañeros, ¿quieren descansar?

- ¡No! Respondieron todos al unísono.

-Falta una hora para llegar al leprosario. Hay mucho que hacer, limpiar, cocinar, curar, alimentar, dialogar; así que reservemos fuerzas.

- ¿Cuánto tiempo hace que está funcionando? 


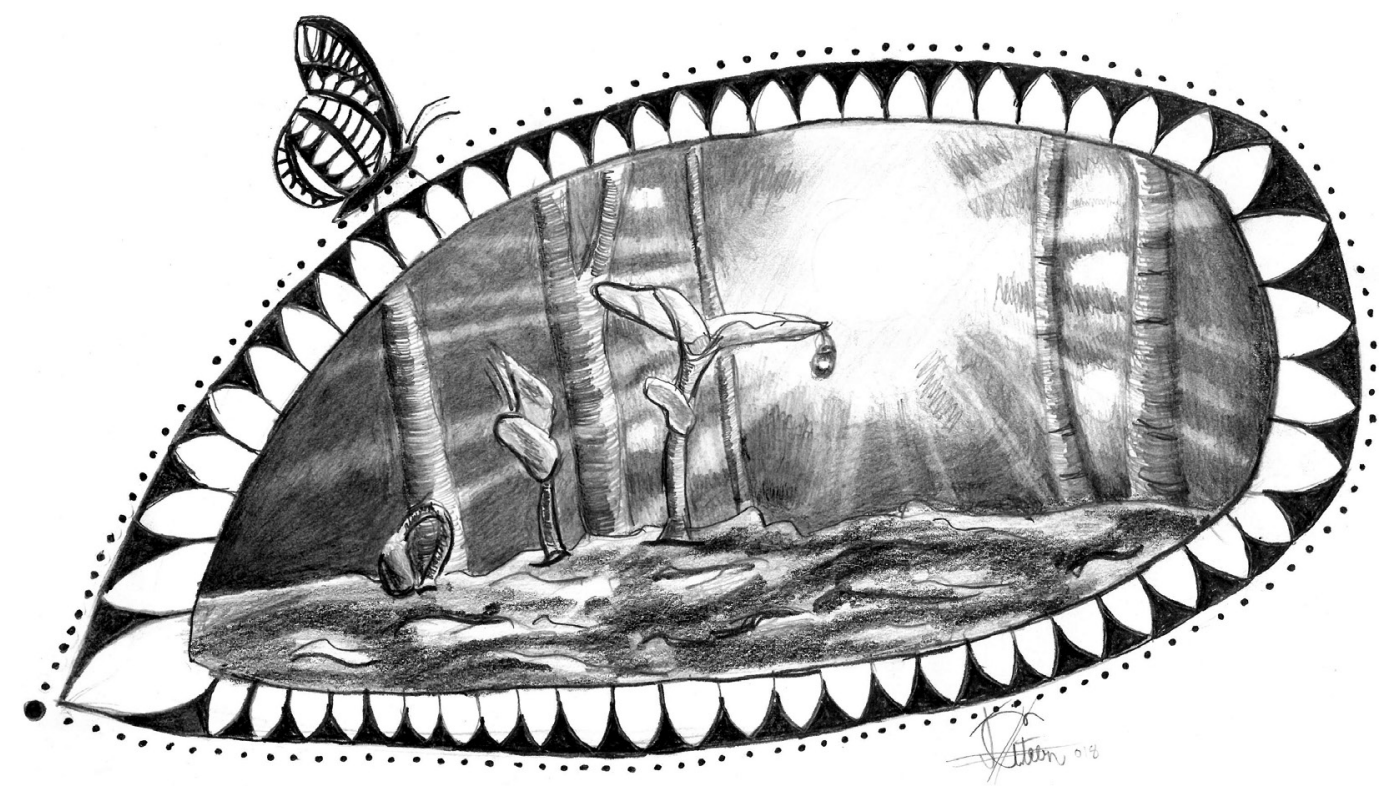

El árbol de naranjo

\section{Jesús Esteban Vargas Cordero \\ Técnica: lápiz, 2018. \\ Ilustra el cuento \\ Héroes y mártires}

- Desde enero de este año. Vienen muchos voluntarios, pero nunca sobra la ayuda.

La mayoría de la población estaba motivada, su compromiso era enorme; los sindicatos rurales y los organismos de ayuda a los campesinos eran una realidad. Raúl pensaba en su compañera y en la aventura que les esperaría en unos cuantos meses. Escribía en su cuadernito observaciones sobre las organizaciones de mujeres, estudiantes y jóvenes.

En poco tiempo había hecho grandes amigos, sus colegas, los compañeros que vivían en las aldeas; había aprendido tanto, más de lo que había transmitido. Eran tan sabios sus alumnos, pero antes se les había negado el derecho de expresarse y habían quedado sometidos al silencio”. ¡Pero no más! Ahora podían decir su palabra.

La estadía de Raúl llegaba a su fin. Tenía que regresar a su hogar, a conocer a su hija. Ya no era la misma persona, tampoco la comunidad era la misma; se sentía tan diferente. Poco a poco se dejó arrullar por el movimiento del bus, la mirada perdida en la inmensa sabana, en las palmas de coyol... Cuando despertó ya estaba al otro lado del río...

-¡Negra! No viene Paula, dice que están muy ocupados.

- Sí, ya hablé con ella. 
- Pero, nosotros vamos para allá a echarles una mano. ¿Qué te parece a vos?

- Sara lo miró con ternura y complicidad. Nos vendría bien un poquito de costa, le respondió con voz cálida.

-¡Claro negra! Ese mar es curador.

Raúl se quedó meditabundo, la última vez que fueron... la última vez que trabajaron juntos en la playa...De pronto sintió sobre su hombro la mano de su compañera.

- Sí, era tan buen amigo de Paula. Dijo ella, como adivinando sus pensamientos. Valiente y comprometido. ¡Qué pecado! Tan joven y lleno de vida.

- Ya van a ser tres meses, el 31 de mayo tiñeron la playa de rojo. ¿Qué será del Caribe sin Jairo? ¡Jueputas cobardes!

Un 18 de mayo, pero hace 33 años se durmió para siempre Georgino Andrade ${ }^{3}$. Días antes había dicho que estaba dispuesto a dar su vida por la seguridad de los brigadistas, recordó melancólico.

Una brisa fresca se coló por la celosía abierta. Un delicioso aroma de café con cardomomo inundó la sala. Recién chorreadito, como te gusta a vos, le dijo Sara, mientras le servía una humeante taza.

2 Jairo Mora, ecologista costarricense, protector de las tortugas baulas y sus huevos en la zona caribeña. Fue asesinado el 31 de mayo de 2013 al parecer por saqueadores de huevos, todavía los móviles del crimen no han sido esclarecidos.

3 Primer Mártir de la Cruzada Nacional de Alfabetización (CNA). Fue parte de los Comités de Defensa Sandinistas (CDS) y de las Milicias Populares. Fue asesinado por ex guardias somocistas el 18 de mayo de 1980.
- Mirá lo que me encontré esta mañana en las cajas de libros de la bodega. Lo abrió y leyó en voz alta.

\section{Cuando anochece y tibia}

una forma de paz se me acerca, es tu recuerdo pan de siembra, hilo místico, con que mis manos quietas son previsoras para mi corazón

- Roque Dalton, dijo Raúl. Vino en mayo, él también se fue en mayo.

- ¡Hombre! Vos tenés una obsesión con las fechas.

- ¡No! Es mayo, algo tiene este mes, algo tiene...

- Lo heredaste de tu abuela. Paula nació un 23 de agosto debería llamarse Rosa, ¿te acordás?

Una sonrisa le iluminó la cara. "Santa Rosa de Lima ahuyentó a unos invasores, a piratas holandeses que iban a tomar la ciudad" recordó Raúl con tono evocativo.

¡Jueputa! Treinta y tres años ya. Yo tenía veintitrés y vos veintidós. Éramos unos chavalos. Y Paula Rosa o Rosa Paula, ya tiene treinta tres. Soltaron una sonora carcajada. Él se levantó, abrió la ventana y prendió un cigarro.

Heredia, 2013. 
